This document is the Accepted Manuscript version of a Published Work that appeared in final form in ACS Sensors, () 2016 American Chemical Society after peer review and technical editing by publisher. To access the final edited and published work see Hoang, M., Huang, P.-J. J., \& Liu, J. (2016). G-Quadruplex DNA for Fluorescent and Colorimetric Detection of Thallium(I). Acs Sensors, 1(2), 137-143. https://doi.org/10.1021/acssensors.5b00147

\title{
A G-quadruplex DNA for Fluorescent and Colorimetric Detection of Thallium(I)
}

Michael Hoang, Po-Jung Jimmy Huang, and Juewen Liu*

Department of Chemistry, Waterloo Institute for Nanotechnology

University of Waterloo

Waterloo, Ontario, N2L 3G1, Canada

Email: liujw@uwaterloo.ca 


\begin{abstract}
Thallium is a highly toxic heavy metal, but its sensing is underexplored compared to its neighbouring elements in the periodic table: lead and mercury. Thallium has two oxidation states. A DNAzyme-based biosensor for $\mathrm{Tl}^{3+}$ was reported recently, representing the first work in this area. However, the most environmentally abundant thallium is monovalent $\mathrm{Tl}^{+}$, which is the focus of this work. Since $\mathrm{Tl}^{+}$is similar to $\mathrm{K}^{+}$in terms of size and charge, G-quadruplex DNAs are herein tested for $\mathrm{Tl}^{+}$detection. First, nine dual fluorophore labelled DNA probes are screened. Among them, a DNA designated PS2.M has the largest increase in the fluorescence resonance energy transfer (FRET) efficiency upon $\mathrm{Tl}^{+}$addition. This FRET-based assay is directly used as a biosensor yielding a detection limit of $59 \mu \mathrm{M} \mathrm{Tl}^{+}$. In comparison, $\mathrm{K}^{+}$had a much lower response and the other tested monovalent metals do not produce a significant signal increase. In addition, a colorimetric sensor was developed based on DNA protected gold nanoparticles. When folded by $\mathrm{Tl}^{+}$, the non-labelled PS2.M DNA cannot effectively adsorb onto gold nanoparticles. This leads to a color change from red to blue upon salt addition. The detection limit is $4.6 \mu \mathrm{M} \mathrm{Tl}^{+}$, and $\mathrm{Tl}^{+}$ spiked in a lake water sample can also be detected. CD spectroscopy is used to further understand $\mathrm{Tl}^{+}$binding to PS2.M. This study demonstrates that DNA can also be used for detecting $\mathrm{Tl}^{+}$, and this work gives rise to a highly effective probe for this purpose.
\end{abstract}

Keywords: thallium, DNA, fluorescence, FRET, gold nanoparticles, biosensors 
Thallium is a trace element with extremely high toxicity. ${ }^{1,2}$ Since its discovery, thallium has been identified as the source of poisoning for many intentional and unintentional deadly incidences. ${ }^{3,4}$ Like most heavy metals, thallium enters the environment often as a by-product of mining. ${ }^{5}$ It is estimated that over 2000 tons of thallium are generated by industrial processes annually. ${ }^{6}$ Additionally, soluble thallium ions can travel deep into soil and be absorbed by crops. Currently, thallium is used in the production of superconductive materials, which has raised growing environmental concerns.

Normal drinking water should contain less than 2.5 to $10 \mathrm{nM}$ thallium as regulated by the US Environmental Protection Agency, while groundwater can routinely reach $\sim 100 \mathrm{nM}$. Concentrations of 1-88 ppm $(5-440 \mu \mathrm{M})$ thallium are reported in river areas for metal mining drainage. ${ }^{2}$ Thallium has two oxidation states. In the environment, thallium exists almost exclusively in the monovalent $\mathrm{Tl}^{+}$state, making detection of $\mathrm{Tl}^{+}$even more analytically relevant. It has been noted for decades that $\mathrm{Tl}^{+}$resembles $\mathrm{K}^{+},{ }^{7}$ which is postulated to be a reason for its toxicity. $\mathrm{Tl}^{+}$and $\mathrm{K}^{+}$have similar ionic radii $\left(\mathrm{Tl}^{+}: 1.54 \AA, \mathrm{K}^{+}: 1.44 \AA\right.$ ), the same charge, and can substitute each other in minerals and some biological reactions. For example, $\mathrm{Tl}^{+}$can replace $\mathrm{Na}^{+}$ and $\mathrm{K}^{+}$in the glutamate transporter excitatory amino acid carrier, ${ }^{8}$ and in quadruplex DNA. ${ }^{9,10}$

While its toxicity is higher than lead, cadmium and even mercury, thallium is often less studied. This is partially attributable to the lack of analytical methods that can accurately measure thallium. ${ }^{2}$ While thallium can be analyzed by a variety of techniques including inductively-coupled plasma mass spectroscopy (ICP-MS), differential pulse anodic stripping voltammetry, and atomic absorption spectrophotometry, ${ }^{11}$ its volatility makes detection more challenging than other metals. In this regard, low-cost biosensors are an attractive solution for its analysis. 
Among the various types of biomolecules available for biosensor development, DNA is highly attractive due to its excellent programmability, versatility in metal coordination, and high stability. ${ }^{12-15}$ DNA-based biosensors for many heavy metals have been reported, including $\mathrm{Pb}^{2+},{ }^{16-}$ ${ }^{18} \mathrm{Hg}^{2+},{ }^{15,}{ }^{19} \mathrm{Ag}^{+},{ }^{20} \mathrm{Cd}^{2+},{ }^{21} \mathrm{Cu}^{2+},{ }^{22}$ and trivalent lanthanide ions. ${ }^{23,}{ }^{24}$ However, thallium detection has not been explored until very recently. We reported a method for detecting $\mathrm{Tl}^{3+}$ using an RNAcleaving DNAzyme and a phosphorothioate (PS)-modified substrate. ${ }^{25}$ This DNAzyme is inactive with the PS substrate. $\mathrm{Tl}^{3+}$ can desulfurize the substrate, thus converting the inactive PS substrate into the active form to yield a fluorescence signal. However, this sensor has no response to $\mathrm{Tl}^{+}$. We previously tested a low concentration of $\mathrm{Tl}+$, and here up to $1 \mathrm{mM} \mathrm{Tl}^{+}$was tested (Figure S1) and still no response was observed. It is speculated that the thiophilicity of $\mathrm{Tl}^{+}$is much lower than that of $\mathrm{Tl}^{3+}$ and thus cannot desulfurize the PS-modified substrate. While it is possible to oxidize $\mathrm{Tl}^{+}$to $\mathrm{Tl}^{3+}$, a direct detection method is more desirable.

Since $\mathrm{Tl}^{+}$is similar to $\mathrm{K}^{+}$, and $\mathrm{K}^{+}$is able to stabilize guanine quadruplex DNA structures, we herein explore whether quadruplex-forming DNAs can be harnessed for $\mathrm{Tl}^{+}$detection. Indeed, we discovered a DNA sequence that has higher affinity for $\mathrm{Tl}^{+}$than for $\mathrm{K}^{+}$and designed both fluorescent and colorimetric sensors.

\section{Materials and Methods}

Chemicals. All the dual-labelled DNA samples were from Gene Link (Hawthorne, NY). The nonlabelled DNAs were from Eurofins (Huntsville, $\mathrm{AL}$ ). TlCl, $\mathrm{TlCl}_{3}, \mathrm{LiCl}, \mathrm{NaCl}, \mathrm{KCl}, \mathrm{RbCl}, \mathrm{CsCl}$, and $\mathrm{NH}_{4} \mathrm{Cl}$ were from Sigma-Aldrich. These metal salts were dissolved in $5 \mathrm{mM}$ HEPES (pH 7.6) to make 13.25 mM stock solutions. 4-(2-Hydroxyethyl)piperazine-1-ethanesulfonic acid (HEPES) 
was from VWR. The $13 \mathrm{~nm}$ gold nanoparticles (AuNPs) were prepared via the citrate reduction method as described previously, ${ }^{26}$ and the initial AuNP concentration was determined to be $13 \mathrm{nM}$. FRET-based detection. FRET-based detection was performed in a $1 \times 1 \mathrm{~cm}$ quartz fluorescence cuvette using a Cary Eclipse fluorometer. All titration tests began with a $3 \mathrm{~mL}$ solution containing $5 \mathrm{mM}$ HEPES (pH 7.6), and $20 \mathrm{nM}$ of DNA. The goal was to monitor the relative change of the two emission peaks with different metal ions. A metal stock solution (13.25 mM) was gradually titrated into the sample and the excitation wavelength of $495 \mathrm{~nm}$ was used (emission from 510 to $630 \mathrm{~nm}$ ). The ratiometric response was calculated by dividing the fluorescence intensity at $585 \mathrm{~nm}$ over that at $518 \mathrm{~nm}$. Experiments were performed in triplicate. For kinetic experiments, a final of $2.35 \mathrm{mM} \mathrm{TlCl}$ was added and the $585 \mathrm{~nm}$ emission intensity was monitored at $12 \mathrm{sec}$ intervals. For the $\mathrm{KCl}$ kinetics, the emission at $518 \mathrm{~nm}$ was monitored. For the interference tests, the starting solution already contained a competing analyte $(2.87 \mathrm{mM})$, and then $50 \mu \mathrm{L}$ of the $\mathrm{TlCl}$ stock solution was add to measure the response. $\mathrm{TlCl}_{3}$ stock $(100 \mathrm{mM})$ was prepared in $1 \% \mathrm{HCl}$. At this concentration, it is not completely soluble. The suspension was agitated and then quickly diluted in Milli-Q water to make $5 \mathrm{mM}$ and $0.1 \mathrm{mM}$ solutions (full solubility achieved under these dilute and acid conditions). Then these stocks were added to the sensor in $5 \mathrm{mM}$ HEPES (pH 7.6).

Colorimetric detection. Colorimetric detection was performed by first mixing $3 \mu \mathrm{L}$ DNA (100 $\mu \mathrm{M}), 3 \mu \mathrm{L}$ metal sock solution (13.25 mM), and $9 \mu \mathrm{L}$ of HEPES buffer (5 mM, pH 7.6). After 1 min, $200 \mu \mathrm{L}$ of AuNP solution was added to the mixture, followed by adding $100 \mu \mathrm{L} \mathrm{NaCl}(200$ $\mathrm{mM})$. The final concentrations for DNA, metal analyte, AuNPs, and added $\mathrm{NaCl}$ were $0.95 \mu \mathrm{M}$, $0.13 \mathrm{mM}, 8.25 \mathrm{nM}$, and $63.49 \mathrm{mM}$ respectively. The color of AuNPs changes to blue upon salt addition if not protected by DNA adsorption. The color of AuNPs was recorded by a digital camera. UV-vis absorption was measured in a $1 \mathrm{~cm}$ quartz cuvette using an Agilent 8453 spectrometer. 
The UV-vis spectra were recorded 5 min after mixing AuNPs with $\mathrm{NaCl}$. The ratiometric response was calculated by dividing the absorbance intensity at $650 \mathrm{~nm}$ by that at $520 \mathrm{~nm}$. Experiments were performed in triplicate. Lake water experiment was performed by mixing $3 \mu \mathrm{L}$ DNA (100 $\mu \mathrm{M}$ ), $0.75 \mu \mathrm{L}$ metal solution, and 11.25 $\mu \mathrm{L}$ Lake Ontario water (no extra HEPES buffer added here). This mixture was added to $200 \mu \mathrm{L}$ of AuNP and then $100 \mu \mathrm{L} \mathrm{NaCl}(200 \mathrm{mM})$ with $5 \mathrm{mM}$ HEPES buffer ( $\mathrm{pH}$ 7.6) was added. The $\mathrm{Tl}^{+}$concentration refers to the concentration before adding AuNPs.

CD spectroscopy. CD spectroscopy was performed in a $1 \mathrm{~cm}$ UV-vis quartz cuvette using a Jasco J-715 Spectrophotometer. Prior to each experiment, a 5 mM HEPES ( $\mathrm{pH}$ 7.6) solution was measured as blank. For each experiment, $200 \mu \mathrm{L}$ of non-labeled DNA $(7.5 \mu \mathrm{M})$ in $5 \mathrm{mM}$ HEPES (pH 7.6) was used. Then a metal salt was added to induce DNA folding. Measurements were performed using a continuous scanning mode $(100 \mathrm{~nm} / \mathrm{min})$ from $220 \mathrm{~nm}$ to $330 \mathrm{~nm}$, and a sensitivity of $100 \mathrm{mdeg}$. The buffer blank was subtracted from the measured signals. Other settings included a $0.5 \mathrm{~nm}$ data pitch, $1 \mathrm{sec}$ response, and $1.0 \mathrm{~nm}$ bandwidth. The average from three scans was plotted.

\section{Results and Discussion}

Screen of a G-quadruplex DNA. Due to the similarity between $\mathrm{Tl}^{+}$and $\mathrm{K}^{+}$, we hypothesize that $\mathrm{Tl}^{+}$might selectively fold some guanine-rich DNA. This DNA conformational change may be utilized for its detection. Due to the limited understanding of thallium/DNA interactions, ${ }^{27,28}$ it is difficult to rationally design an oligonucleotide to test our hypothesis. Therefore, we screened a few common quadruplex-forming sequences. We employed a fluorescence resonance energy transfer (FRET)-based assay for this screen, so that an optimal sequence can be directly used as a 
biosensor. These DNAs were labeled at their two termini with a FAM (carboxyfluorescein) and a TMR (tetramethylrhodamine), respectively. $\mathrm{Tl}^{+}$-induced folding might reduce the end-to-end distance and thus increase the FRET efficiency (Figure 1A). FAM is the FRET donor, transferring its energy to the nearby TMR acceptor, and the FRET efficiency depends on the inter-fluorophore distance. In this study, a total of six G-rich DNAs were used (Figure 1B). For example, the PS2.M DNA was originally identified as an aptamer for binding hemin, ${ }^{29,}{ }^{30}$ while $\mathrm{K}^{+}$-Apt is from a previous paper used for sensing $\mathrm{K}^{+} .{ }^{31}$ AS1411 is an aptamer targeting nucleolin on cancer cells, ${ }^{32}$ while AS1411-6 contains two more guanine repeating units based on AS1411. In addition, three control sequences were also included for comparison (the last three sequences in Figure 1B). AdeApt-FT is the adenosine aptamer, ${ }^{33} \mathrm{Hg}$-Apt-FT binds $\mathrm{Hg}^{2+},{ }^{15}$ and Ctrl-DNA-FT is a random sequence without known molecular binding property.

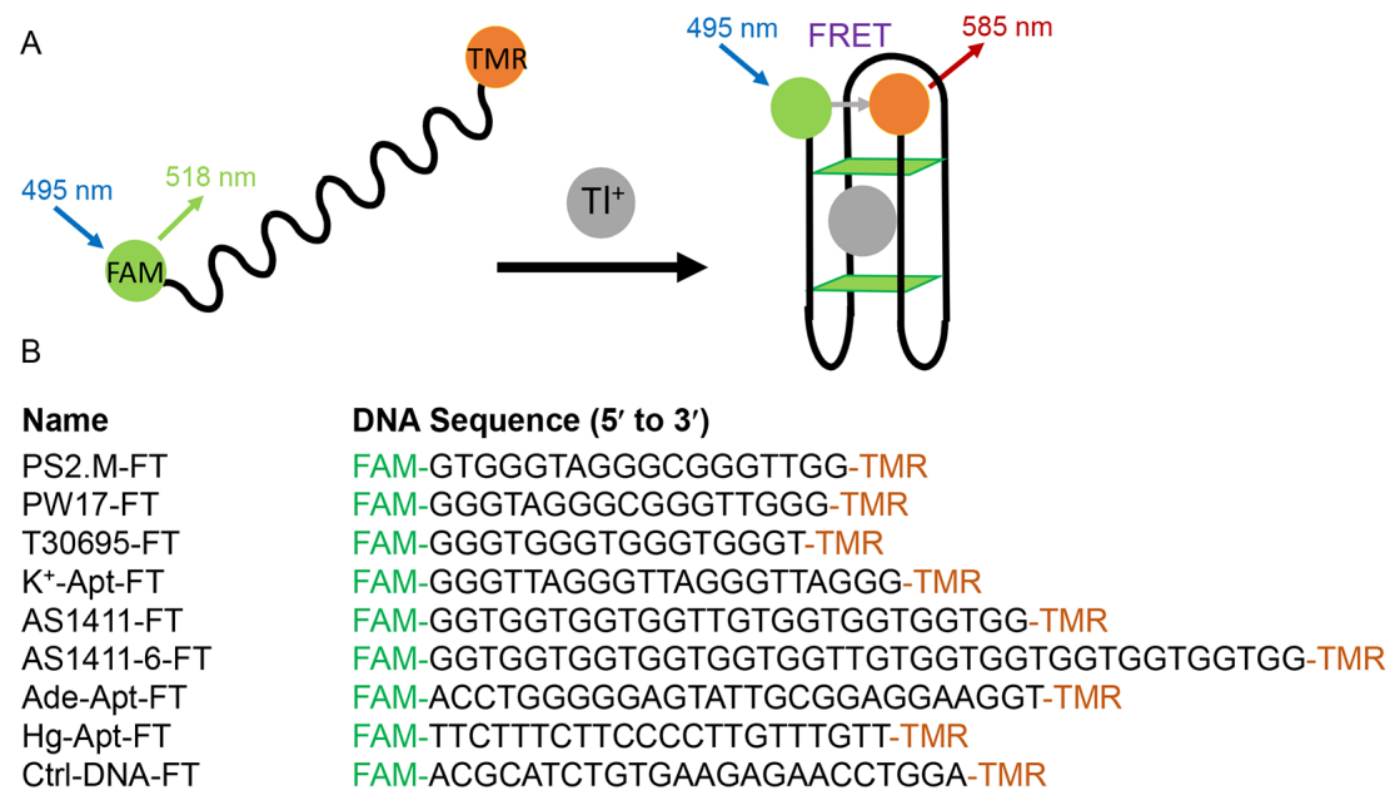

Figure 1. (A) A scheme showing $\mathrm{Tl}^{+}$-induced DNA conformational change into a G-quadruplex and the accompanying enhanced FRET efficiency. (B) DNA sequences and modifications used in 
this work for the FRET-based probe screening. The first six are G quadruplex-forming DNAs, and the last three are controls for comparison.

We first scanned the steady-state fluorescence emission spectra of these nine DNAs in the presence and absence of $\mathrm{Tl}^{+}$. For example, the black spectrum in Figure $2 \mathrm{~A}$ was obtained by exciting the PS2.M-FT DNA at $492 \mathrm{~nm}$, yielding two peaks at $518 \mathrm{~nm}$ and $585 \mathrm{~nm}$, respectively. The $518 \mathrm{~nm}$ peak is from the FAM emission and the 585 peak is mainly due to energy transfer from FAM to TMR. After adding $\mathrm{Tl}^{+}$, the FAM peak dropped significantly, while the TMR peak increased concomitantly, indicating that $\mathrm{Tl}^{+}$can shorten the distance between these two fluorophores. Therefore, this DNA might be a good probe for $\mathrm{Tl}^{+}$based on the scheme in Figure 1A. When the same concentration of $\mathrm{K}^{+}$was added (Figure 2B), the FAM peak dropped only slightly and the TMR peak lacked the correlated increase. This suggests either a weaker binding affinity or a different way of DNA folding occurring when interacting with $\mathrm{K}^{+}$. This difference is useful for the distinction of these two ions.

The same experiment was performed using all the other DNA sequences, and the emission intensity ratios of the two peaks before and after adding $\mathrm{Tl}^{+}$were plotted (Figure $2 \mathrm{C}$ ). The initial FRET efficiency is quite different for these nine DNAs (the black bars), indicating that they have a broad range of end-to-end distance distribution. All the sequences have higher FRET efficiency after adding $\mathrm{Tl}^{+}$, indicating DNA folding and shorter end-to-end distance. Most G-rich DNA displayed an obvious FRET change, while the control DNAs changed to a lesser extent. An ideal probe should have a large signal change by $\mathrm{Tl}^{+}$, and we conclude that PS2.M-FT is an optimal 
sequence among the ones we tested (yielding 3.4-fold signal change). The $\mathrm{K}^{+}$-Apt DNA has the second highest response (2.6-fold).

We then studied the kinetics of signalling upon metal addition. After monitoring the background fluorescence for $2 \mathrm{~min}, \mathrm{Tl}^{+}$was added and the rise of the $585 \mathrm{~nm}$ peak followed the first-order reaction kinetics with a rate constant of $2.6 \mathrm{~min}^{-1}$ (Figure 2D, red triangles). It took $\sim 1$ min for the signal to stabilize. For comparison, $\mathrm{K}^{+}$induced a faster signal change (black dots). The drop of the $518 \mathrm{~nm}$ peak followed a rate constant of $7.5 \mathrm{~min}^{-1}$, and a stable signal was achieved in just $12 \mathrm{sec}$. It was reported that $\mathrm{Tl}^{+}$binds to halides such as chloride more tightly than $\mathrm{K}^{+}$does. ${ }^{7}$ This may explain its slower kinetics in binding to DNA, since the associated $\mathrm{Cl}^{-}$ligands need to be displaced before $\mathrm{Tl}^{+}$entering the G-quadruplex cavity. Overall, the kinetics is sufficiently fast for analytical applications.
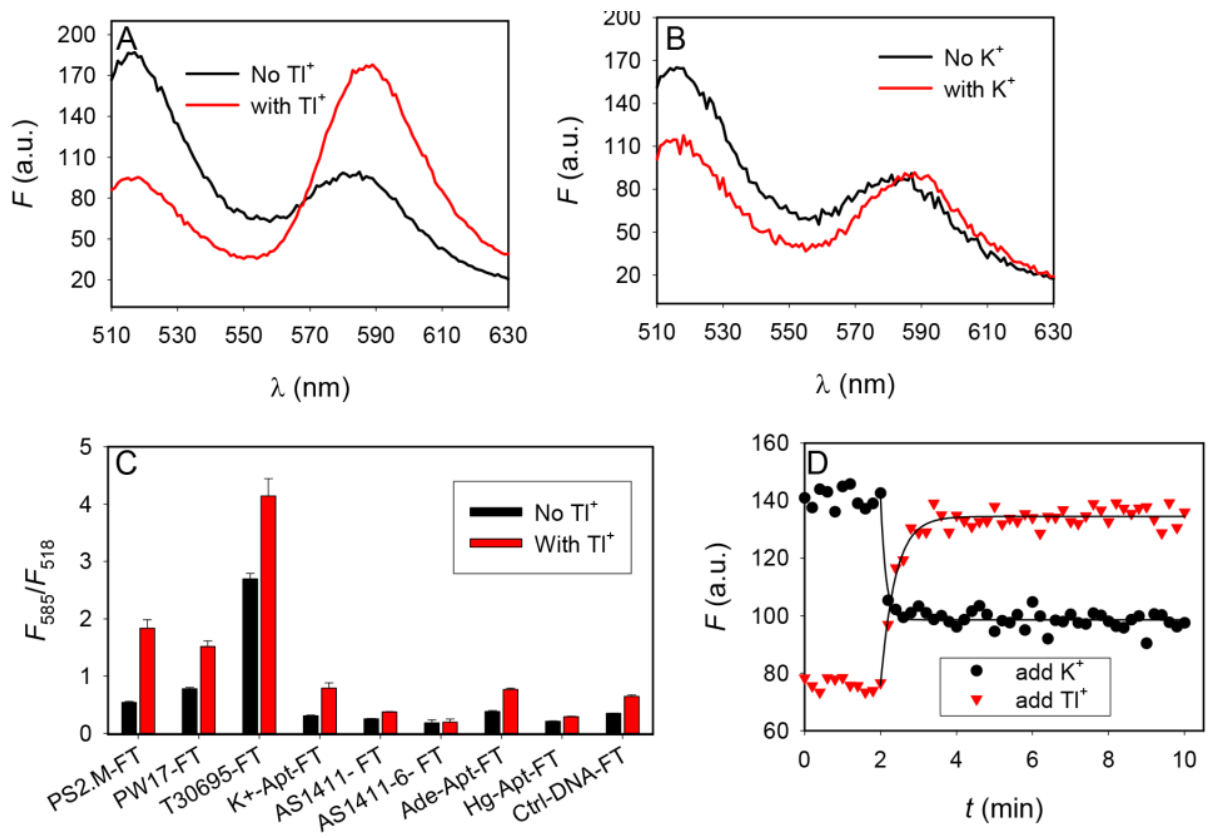

Figure 2. The PS2.M-FT fluorescence emission spectra before and after adding a final concentration of (A) $2.36 \mathrm{mM} \mathrm{TlCl}$, or (B) adding the same concentration of $\mathrm{KCl}$. Reaction buffer: 
5 mM HEPES pH 7.6 with $20 \mathrm{nM}$ PS2.M-FT DNA. (C) Response of the various DNA probes to $\mathrm{Tl}^{+}$. The ratios of the two fluorescence peaks are plotted. (D) Kinetics of the increase of the 585 nm peak of PS2.M after adding $\mathrm{Tl}^{+}$and the drop of the $518 \mathrm{~nm}$ peak after adding $\mathrm{K}^{+}$.

FRET-based $\mathrm{Tl}^{+}$detection. Since PS2.M-FT has the highest response to $\mathrm{Tl}^{+}$among all the tested DNAs, we further studied it for $\mathrm{Tl}^{+}$detection. First, metal selectivity was measured. We monitored the fluorescence ratio as a function of concentration of each monovalent cation (Figure 3A). Indeed, $\mathrm{Tl}^{+}$has the highest response followed by $\mathrm{K}^{+}$. At $2.4 \mathrm{mM}, \mathrm{Tl}^{+}$has a ratio greater than 1.8 , while $\mathrm{K}^{+}$ is below 0.9 (note that the background value is $\sim 0.6$ ). The other ions did not show a significant response and their signal remained as the background level. This suggests that the signal change is likely due to G-quadruplex formation, since $\mathrm{Tl}^{+}$and $\mathrm{K}^{+}$are the most efficient for this reaction. Next, an interference assay was carried out, where the DNA probe was first incubated with each competing metal, followed by adding $\mathrm{Tl}^{+}$(Figure 3B). In all the samples, $\mathrm{Tl}^{+}$produced a significant signal increase. Therefore, these metal ions do not interfere with $\mathrm{Tl}^{+}$detection. We also tested the response of this probe to $\mathrm{Tl}^{3+}$ (Figure 3C); the ratio remained unchanged with up to $16 \mu \mathrm{M} \mathrm{Tl} l^{3+}$, which is consistent with the lack of strong interaction between $\mathrm{Tl}^{3+}$ and DNA. ${ }^{25} \mathrm{Tl}^{3+}$ started to precipitate at even higher concentrations and thus was not further measured.

Some divalent metal ions, especially $\mathrm{Pb}^{2+}$, are also highly potent in stabilizing Gquadruplex. ${ }^{34}$ For this particular PS2.M DNA, $\mathrm{Pb}^{2+}$ was reported to be also a strong binder. ${ }^{35} \mathrm{We}$ titrated $\mathrm{Pb}^{2+}$ into the PS2.M-FT DNA, but only observed fluorescence quenching of both fluorophores with no indicating of enhanced FRET (Figure S2). It is likely that the DNA folds into a different conformation with $\mathrm{Pb}^{2+}$, which is also supported by the previous work. ${ }^{35}$ 
After confirming selectivity, we then measured sensitivity. Figure 3A shows that the dynamic range goes up to $\sim 1 \mathrm{mM} \mathrm{Tl}{ }^{+}$. After that, the signal change becomes much smaller. We then did a finer titration at lower metal concentrations up to $300 \mu \mathrm{M} \mathrm{Tl}^{+}$, and a linear relationship was observed (Figure 3D). By calculating the slope of this line and the standard deviation of background variation $(\sigma)$, the detection limit is $59 \mu \mathrm{M} \mathrm{Tl}^{+}$using $3 \sigma /$ slope.
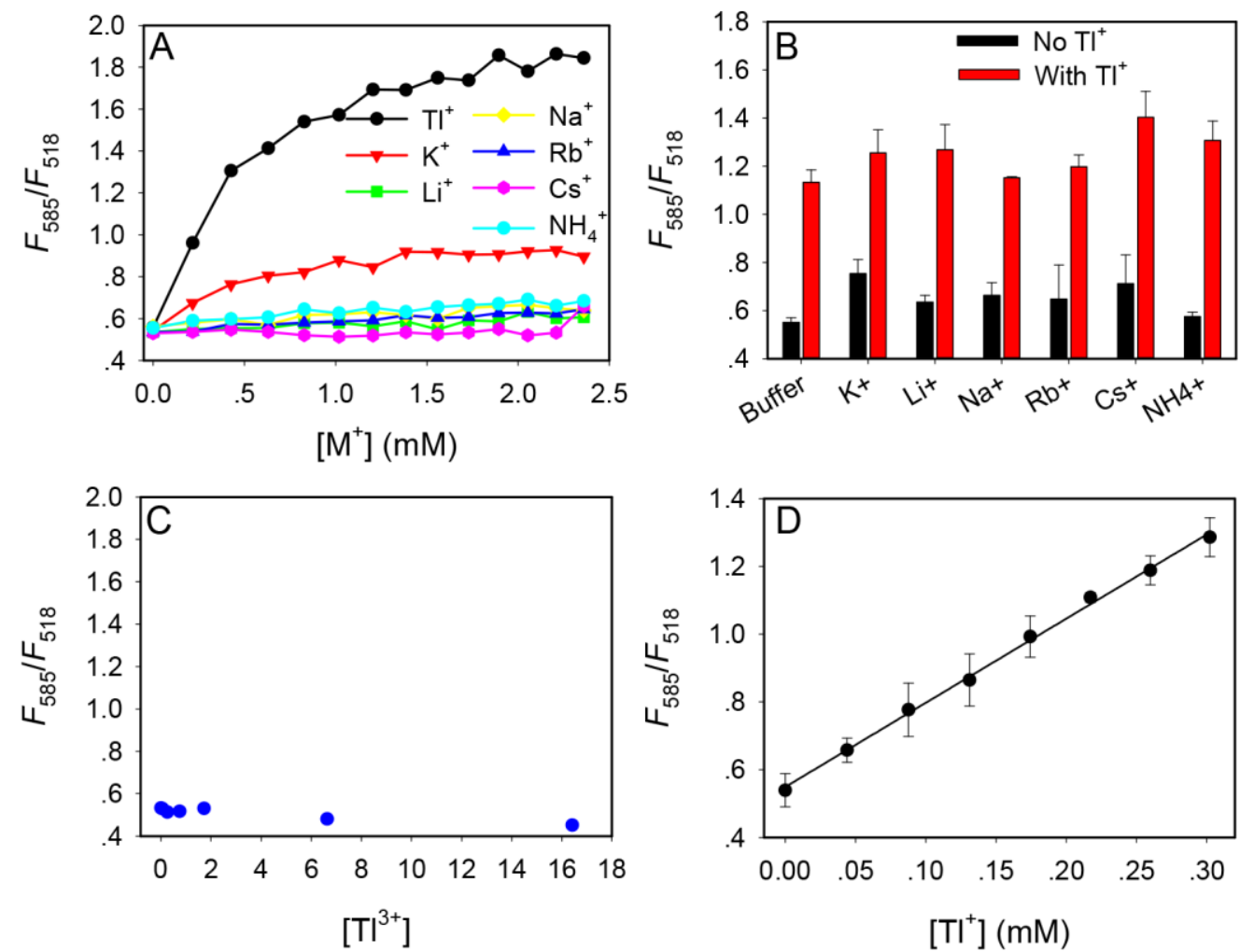

Figure 3. (A) The PS2.M-based sensor selectivity test at various metal concentrations. (B) A competitive test. The concentration of the competing salts is $2.87 \mathrm{mM}$ and then a final concentration of $0.22 \mathrm{mM} \mathrm{Tl}^{+}$is added. All the experiments are run in triplicate in $5 \mathrm{mM} \mathrm{HEPES}$ buffer (pH 7.6) with 20 nM DNA probe. (C) Response of the sensor to $\mathrm{Tl}^{3+}$. (D) Sensor sensitivity test at low $\mathrm{Tl}^{+}$concentrations. 
Colorimetric detection. While FRET is a sensitive method, the cost of dual-labeled DNA probes is relatively high and the detection still requires a fluorometer. To further improve the sensing method, we also aimed to design a colorimetric biosensor using this $\mathrm{Tl}^{+}$-induced DNA folding. Gold nanoparticles (AuNPs) are particularly attractive for this purpose since they have extremely high extinction coefficients and aggregation-induced color change. ${ }^{36-38}$ Dispersed AuNPs have an intense red color due to the surface plasmon effect. It has been well established that the rate of DNA adsorption by citrate-capped AuNPs is a strong function of DNA conformation. ${ }^{39-41}$ DNAs without stable secondary structures are more efficiently adsorbed and thus allow higher colloidal stability of AuNPs against salt-induced aggregation (Figure 4A). If the DNA is folded by $\mathrm{Tl}^{+}$to inhibit its adsorption, AuNPs are more easily aggregated by the added salt and thus change color to blue. This method has been used to detect a diverse range of analytes by using DNA aptamer probes. $^{42-44}$

To test this sensing mechanism, we respectively incubated the non-labeled PS2.M DNA with $\mathrm{Tl}^{+}$as well as other monovalent metal ions. Then citrate-capped $13 \mathrm{~nm}$ AuNPs were added followed by the addition of a concentrated $\mathrm{NaCl}$ solution. The resulting color was documented by a digital camera (Figure 4B). Indeed, we observed an intense purple color for the $\mathrm{Tl}^{+}$sample, while all the other samples remained red as the control without any pre-incubated monovalent metal ions. It appears that the free PS2.M DNA was efficiently adsorbed by the AuNPs in the absence of $\mathrm{Tl}^{+}$, since it can protect the AuNPs. $\mathrm{Tl}^{+}$inhibits this protection, which is consistent with the mechanism in Figure 4A. This successful colorimetric detection adds further weight to the hypothesis that PS2.M has in fact a high binding affinity towards $\mathrm{Tl}^{+}$. The UV-vis spectra of the AuNP samples with and without $\mathrm{Tl}^{+}$are shown in Figure 4C, where a clear shift of the $520 \mathrm{~nm}$ peak to longer 
wavelength is observed for the $\mathrm{Tl}^{+}$added sample. The increase in $650 \mathrm{~nm}$ extinction and decrease at the $520 \mathrm{~nm}$ peak upon $\mathrm{Tl}^{+}$addition allows for the ratiometric measurement (Figure 4D); the $\mathrm{Tl}^{+}$ containing sample has the highest ratio, while the other samples are at the background level.

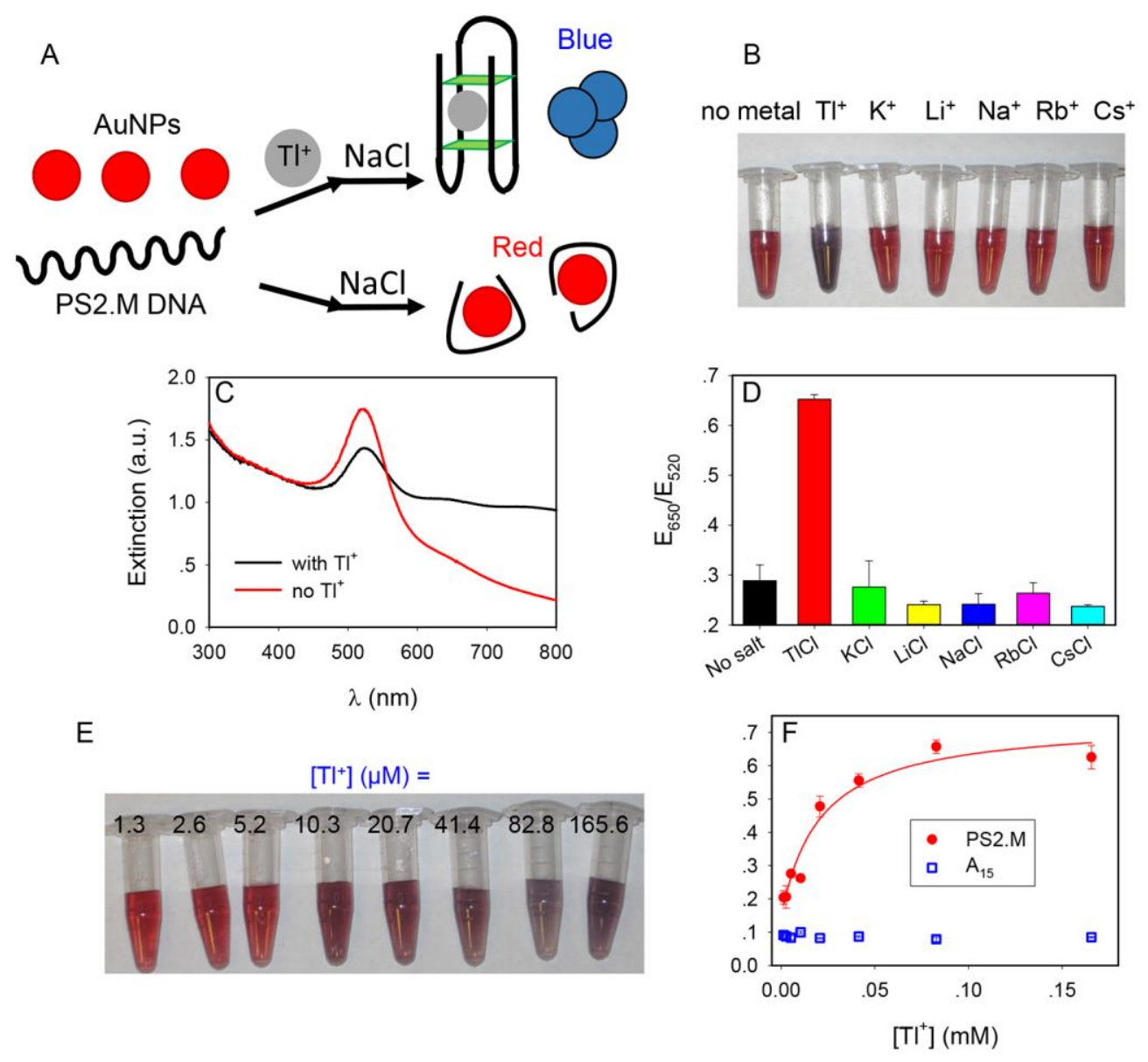

Figure 4. (A) A scheme of colorimetric sensor design. The PS2.M DNA is folded by $\mathrm{Tl}^{+}$, retarding its adsorption by AuNPs, leading to AuNP aggregation by salt, and resulting in a color change to blue. Without $\mathrm{Tl}^{+}$, the AuNPs are protected by the DNA. (B) Sensor color response to $2.65 \mathrm{mM}$ various monovalent metal ions. (C) UV-vis spectra of the sensor samples with and without 2.65 $\mathrm{mM} \mathrm{Tl}{ }^{+}$. (D) Quantification of the color change based on the extinction ratio at $650 \mathrm{~nm}$ over 520 $\mathrm{nm}$. The DNA and metal ions were mixed in a $5 \mathrm{mM}$ HEPES (pH 7.6) buffer. The final reagent 
concentrations were PS2.M DNA $=0.95 \mu \mathrm{M}, \mathrm{AuNP}=8.3 \mathrm{nM}, \mathrm{NaCl}=64 \mathrm{mM}$, and $\mathrm{Tl}^{+}$or other metal ions $=0.13 \mathrm{mM}$. The final volume was $315 \mu \mathrm{L}$. (E) The response of the colorimetric sensor to various $\mathrm{Tl}^{+}$concentrations. (F) A UV-vis based ratiometric quantification of $\mathrm{Tl}^{+}$titration using the PS2.M or $\mathrm{A}_{15}$ DNA. The listed $\mathrm{Tl}^{+}$concentration is before adding AuNPs and salt. After adding, the $\mathrm{Tl}^{+}$is diluted by $\sim 30$-fold.

Having demonstrated the feasibility and selectivity of this colorimetric sensor, the sensitivity was measured next. A gradual color progression from red to purple and then blue was observed with increasing of $\mathrm{Tl}^{+}$concentration (Figure 4E). Using UV-vis spectroscopy, the color change was quantified (Figure $4 \mathrm{~F}$, red dots), and this sensor can detect up to $\sim 100 \mu \mathrm{M} \mathrm{Tl}^{+}$. The detection limit was $4.6 \mu \mathrm{M} \mathrm{Tl}^{+}$. Therefore, this colorimetric sensor is even more sensitive than the above FRET-based detection. With more than $10 \mu \mathrm{M} \mathrm{Tl}^{+}$, the color change can be readily observed by the naked eye. As a control to confirm the sensing mechanism, the same experiment was repeated using an $\mathrm{A}_{15}$ DNA (i.e. 15 adenines). The visual results showed that $\mathrm{Tl}^{+}$had little effect on the color of AuNPs and all the samples remained red (data not shown). The UV-vis spectroscopy tests showed minimal response towards $\mathrm{Tl}^{+}$as well (Figure 4F, blue dots). Therefore, it is the specific binding between $\mathrm{Tl}^{+}$and PS2.M responsible for the observed color change.

CD Spectroscopy. It is interesting to see that $\mathrm{Tl}^{+}$and $\mathrm{K}^{+}$gave different responses in both the FRET and the colorimetric assays. To further understand metal binding, we characterized the folding of the DNA using circular dichroism (CD) spectroscopy. The DNA was dissolved in 5 mM HEPES buffer, the same as our sensing condition. In this buffer, the free PS2.M DNA showed two positive peaks at $250 \mathrm{~nm}$ and $295 \mathrm{~nm}$, and a negative peak at $264 \mathrm{~nm}$ (Figure 5A, black spectrum). These features agree with the group III anti-parallel quadruplex structure. ${ }^{45}$ Our $5 \mathrm{mM}$ HEPES buffer 
already contained $2.5 \mathrm{mM} \mathrm{Na}^{+}$at $\mathrm{pH} 7.6$, and it appears that a fraction of the DNA was already folded by this background $\mathrm{Na}^{+}{ }^{46}$ After adding $\mathrm{Tl}^{+}$, the two positive peaks increased and the negative peak slightly decreased. Therefore, $\mathrm{Tl}^{+}$has shifted the equilibrium and folded more DNA into the quadruplex. Note that unfolded DNA does not generate much CD signal and the stronger signal can only be attributed to a greater amount of DNA being folded. Adding $\mathrm{K}^{+}$only raised the $290 \mathrm{~nm}$ positive peak (Figure 5B), while adding $\mathrm{Na}^{+}$did not change the folding of this DNA (Figure 5C). The FRET study and the $\mathrm{CD}$ data both indicate that $\mathrm{Tl}^{+}$is the most efficient in folding the PS2.M DNA.
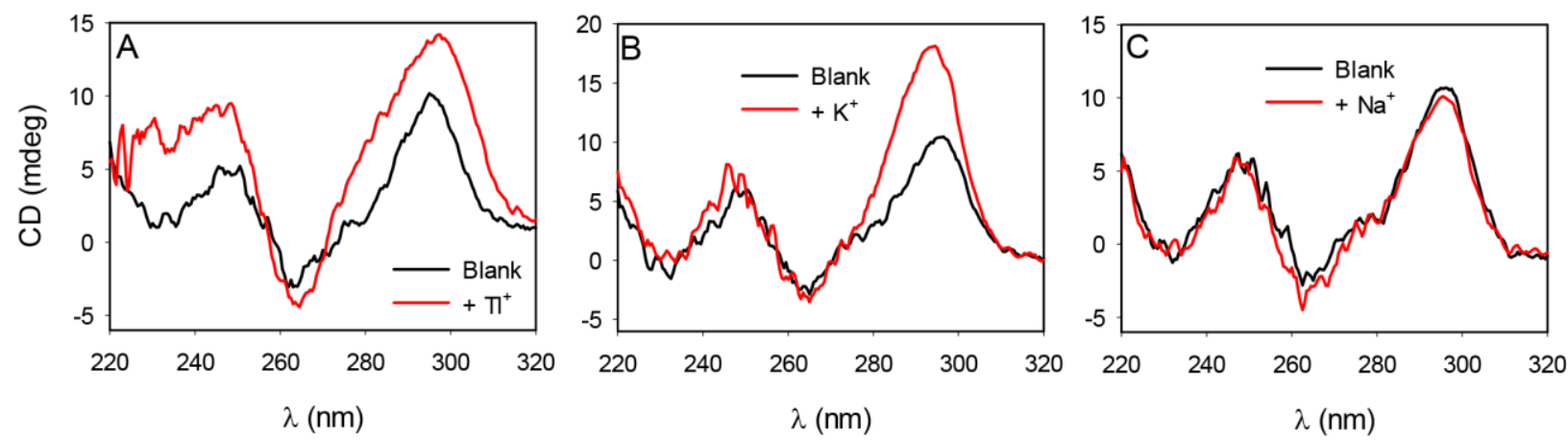

Figure 5. CD spectra of the PS2.M DNA $(7.5 \mu \mathrm{M})$ before and after adding $0.22 \mathrm{mM}(\mathrm{A}) \mathrm{Tl}^{+}$, (B) $\mathrm{K}^{+}$, and $(\mathrm{C}) \mathrm{Na}^{+}$.

\section{Conclusions}

In summary, we screened multiple G-quadruplex DNAs using a FRET-based assay for $\mathrm{Tl}^{+}$ detection. Of these sequences, the PS2.M DNA was selected due to its significant change in the FRET efficiency upon $\mathrm{Tl}^{+}$binding. While the signaling kinetics for $\mathrm{Tl}^{+}$is $\sim 3$-fold slower than that for $\mathrm{K}^{+}$, it reaches a stable signal in $1 \mathrm{~min}$. This sensor has a detection limit of $59 \mu \mathrm{M} \mathrm{Tl}^{+}$. Further 
$\mathrm{Tl}^{+}$-induced DNA conformational change and binding was characterized by $\mathrm{CD}$ spectroscopy, indicating a significant difference between $\mathrm{Tl}^{+}$and the rest of the monovalent metal ions in promoting the DNA folding into G-quadruplex. We further designed a colorimetric sensor using the same DNA sequence but without any fluorescence label. The PS2.M DNA adsorption by AuNPs was inhibited by $\mathrm{Tl}^{+}$due to DNA folding, and a red-to-blue color change was observed upon salt addition. The colorimetric detection method has a detection limit of $4.6 \mu \mathrm{M} \mathrm{Tl}^{+}$. These detection limits are unlikely to be enough for monitoring drinking water, which requires detection of lower than $10 \mathrm{nM} \mathrm{Tl}^{+}$. On the other hand, many mining related regions contain much higher $\mathrm{Tl}^{+}$ and these sensors fit in the detection range of those applications. For drinking water monitoring,

sample enrichment or oxidation to $\mathrm{Tl}^{3+}$ might be needed. This is the first report on DNA-based sensor for $\mathrm{Tl}^{+}$detection, and it has enhanced our understanding on $\mathrm{Tl}^{+} / \mathrm{DNA}$ interactions.

\section{Supporting Information}

The Supporting Information is available free of charge on the ACS Publication website at DOI: DNAzyme-based assay of $\mathrm{Tl}^{+}$and $\mathrm{Tl}^{3+}$ at high metal concentrations, sensor response to $\mathrm{Pb}^{2+}$, and sensor response in Lake Ontario water. (PDF)

\section{Acknowledgement}

Funding for this work is from the Ontario Ministry of Research \& Innovation, and the Natural Sciences and Engineering Research Council of Canada (NSERC, Discovery Grant: 386326 and Strategic Project Grant: STPGP-447472-2013 055766). 


\section{References}

(1) Rodriguez-Mercado, J. J.; Altamirano-Lozano, M. A., Genetic Toxicology of Thallium: A Review. Drug. Chem. Toxicol. 2013, 36, 369-383.

(2) Peter, A. L. J.; Viraraghavan, T., Thallium: A Review of Public Health and Environmental Concerns. Environ. Int. 2005, 31, 493-501.

(3) Li, S.; Huang, W.; Duan, Y.; Xing, J.; Zhou, Y., Human Fatality Due to Thallium Poisoning: Autopsy, Microscopy, and Mass Spectrometry Assays. J. Forensic. Sci. 2015, 60, 247-251.

(4) Tsai, Y.-T.; Huang, C.-C.; Kuo, H.-C.; Wang, H.-M.; Shen, W.-S.; Shih, T.-S.; Chu, N.-S., Central Nervous System Effects in Acute Thallium Poisoning. Neurotoxicology 2006, 27, 291-295.

(5) Zitko, V., Toxicity and Pollution Potential of Thallium. Sci. Total Environ. 1975, 4, 185192.

(6) Kazantzis, G., Thallium in the Environment and Health Effects. Environ. Geochem. Health 2000, 22, 275-280.

(7) Lee, A. G., The Coordination Chemistry of Thallium(I). Coord. Chem. Rev. 1972, 8, 289349.

(8) Tao, Z.; Gameiro, A.; Grewer, C., Thallium Ions Can Replace Both Sodium and Potassium Ions in the Glutamate Transporter Excitatory Amino Acid Carrier 1. Biochemistry 2008, 47, 12923-12930.

(9) Gill, M. L.; Strobel, S. A.; Loria, J. P., Crystallization and Characterization of the Thallium Form of the Oxytricha Nova G-Quadruplex. Nucleic Acids Res. 2006, 34, 4506-4514. 
(10) Gill, M. L.; Strobel, S. A.; Loria, J. P., (T1)-T-205 NMR Methods for the Characterization of Monovalent Cation Binding to Nucleic Acids. J. Am. Chem. Soc. 2005, 127, 1672316732.

(11) Galvan-Arzate, S.; Santamaria, A., Thallium Toxicity. Toxicol. Lett. 1998, 99, 1-13.

(12) Liu, J.; Cao, Z.; Lu, Y., Functional Nucleic Acid Sensors. Chem. Rev. 2009, 109, 19481998.

(13) Zhang, X.-B.; Kong, R.-M.; Lu, Y., Metal Ion Sensors Based on Dnazymes and Related DNA Molecules. Annu. Rev. Anal. Chem. 2011, 4, 105-128.

(14) Lin, Y. W.; Huang, C. C.; Chang, H. T., Gold Nanoparticle Probes for the Detection of Mercury, Lead and Copper Ions. Analyst 2011, 136, 863-871.

(15) Ono, A.; Togashi, H., Molecular Sensors: Highly Selective Oligonucleotide-Based Sensor for Mercury(II) in Aqueous Solutions. Angew. Chem., Int. Ed. 2004, 43, 4300-4302.

(16) Li, J.; Lu, Y., A Highly Sensitive and Selective Catalytic DNA Biosensor for Lead Ions. $J$. Am. Chem. Soc. 2000, 122, 10466-10467.

(17) Xiao, Y.; Rowe, A. A.; Plaxco, K. W., Electrochemical Detection of Parts-Per-Billion Lead Via an Electrode-Bound DNAzyme Assembly. J. Am. Chem. Soc. 2007, 129, 262-263.

(18) Wang, H.; Kim, Y.; Liu, H.; Zhu, Z.; Bamrungsap, S.; Tan, W., Engineering a Unimolecular DNA-Catalytic Probe for Single Lead Ion Monitoring. J. Am. Chem. Soc. 2009, 131, 8221-8226.

(19) Hollenstein, M.; Hipolito, C.; Lam, C.; Dietrich, D.; Perrin, D. M., A Highly Selective DNAzyme Sensor for Mercuric Ions. Angew. Chem., Int. Ed. 2008, 47, 4346 - 4350. 
(20) Ono, A.; Cao, S.; Togashi, H.; Tashiro, M.; Fujimoto, T.; Machinami, T.; Oda, S.; Miyake, Y.; Okamoto, I.; Tanaka, Y., Specific Interactions between Silver(I) Ions and CytosineCytosine Pairs in DNA Duplexes. Chem. Commun. 2008, 4825-4827.

(21) Huang, P.-J. J.; Liu, J., Rational Evolution of $\mathrm{Cd}^{2+}$-Specific DNAzymes with Phosphorothioate Modified Cleavage Junction and $\mathrm{Cd}^{2+}$ Sensing. Nucleic Acids Res. 2015, 43, 6125-6133.

(22) Liu, J.; Lu, Y., A DNAzyme Catalytic Beacon Sensor for Paramagnetic $\mathrm{Cu}^{2+}$ Ions in Aqueous Solution with High Sensitivity and Selectivity. J. Am. Chem. Soc. 2007, 129, 9838-9839.

(23) Huang, P.-J. J.; Lin, J.; Cao, J.; Vazin, M.; Liu, J., Ultrasensitive DNAzyme Beacon for Lanthanides and Metal Speciation. Anal. Chem. 2014, 86, 1816-1821.

(24) Huang, P.-J. J.; Vazin, M.; Matuszek, Ż.; Liu, J., A New Heavy Lanthanide-Dependent DNAzyme Displaying Strong Metal Cooperativity and Unrescuable Phosphorothioate Effect. Nucleic Acids Res. 2015, 43, 461-469.

(25) Huang, P.-J. J.; Vazin, M.; Liu, J., Desulfurization Activated Phosphorothioate DNAzyme for the Detection of Thallium. Anal. Chem. 2015, 87, 10443-10449.

(26) Liu, J.; Lu, Y., Preparation of Aptamer-Linked Gold Nanoparticle Purple Aggregates for Colorimetric Sensing of Analytes. Nat. Protoc. 2006, 1, 246-252.

(27) Ouameur, A. A.; Nafisi, S.; Mohajerani, N.; Tajmir-Riahi, H. A., Thallium-DNA Complexes in Aqueous Solution. Major or Minor Groove Binding. J. Biomol. Struct. Dyn. 2003, 20, 561-565.

(28) Howerton, S. B.; Sines, C. C.; VanDerveer, D.; Williams, L. D., Locating Monovalent Cations in the Grooves of B-DNA. Biochemistry 2001, 40, 10023-10031. 
(29) Li, Y.; Geyer, C. R.; Sen, D., High-Specificity Recognition of Anionic Porphyrins by DNA Aptamers. Biochemistry 1996, 35, 6911-6922.

(30) Travascio, P.; Li, Y.; Sen, D., DNA-Enhanced Peroxidase Activity of a DNA AptamerHemin Complex. Chem. Biol. 1998, 5, 505-517.

(31) Ueyama, H.; Takagi, M.; Takenaka, S., A Novel Potassium Sensing in Aqueous Media with a Synthetic Oligonucleotide Derivative. Fluorescence Resonance Energy Transfer Associated with Guanine Quartet-Potassium Ion Complex Formation. J. Am. Chem. Soc. 2002, 124, 14286-14287.

(32) Bates, P. J.; Laber, D. A.; Miller, D. M.; Thomas, S. D.; Trent, J. O., Discovery and Development of the G-Rich Oligonucleotide AS1411 as a Novel Treatment for Cancer. Exp. Mol. Pathol. 2009, 86, 151-164.

(33) Huizenga, D. E.; Szostak, J. W., A DNA Aptamer That Binds Adenosine and ATP. Biochemistry 1995, 34, 656-665.

(34) Smirnov, I.; Shafer, R. H., Lead Is Unusually Effective in Sequence-Specific Folding of DNA. J. Mol. Biol. 2000, 296, 1-5.

(35) Li, T.; Wang, E.; Dong, S., Lead(II)-Induced Allosteric G-Quadruplex DNAzyme as a Colorimetric and Chemiluminescence Sensor for Highly Sensitive and Selective $\mathrm{Pb}^{2+}$ Detection. Anal. Chem. 2010, 82, 1515-1520.

(36) Rosi, N. L.; Mirkin, C. A., Nanostructures in Biodiagnostics. Chem. Rev. 2005, 105, $1547-$ 1562.

(37) Zhao, W.; Brook, M. A.; Li, Y., Design of Gold Nanoparticle-Based Colorimetric Biosensing Assays. ChemBioChem 2008, 9, 2363-2371. 
(38) Li, D.; Song, S. P.; Fan, C. H., Target-Responsive Structural Switching for Nucleic AcidBased Sensors. Acc. Chem. Res. 2010, 43, 631-641.

(39) Li, H.; Rothberg, L. J., DNA Sequence Detection Using Selective Fluorescence Quenching of Tagged Oligonucleotide Probes by Gold Nanoparticles. Anal. Chem. 2004, 76, 54145417.

(40) Li, H.; Rothberg, L. J., Label-Free Colorimetric Detection of Specific Sequences in Genomic DNA Amplified by the Polymerase Chain Reaction. J. Am. Chem. Soc. 2004, 126, 10958-10961.

(41) Liu, J., Adsorption of DNA onto Gold Nanoparticles and Graphene Oxide: Surface Science and Applications. Phys. Chem. Chem. Phys. 2012, 14, 10485-10496.

(42) Zhang, J.; Wang, L.; Zhang, H.; Boey, F.; Song, S.; Fan, C., Aptamer-Based Multicolor Fluorescent Gold Nanoprobes for Multiplex Detection in Homogeneous Solution. Small 2010, 6, 201-204.

(43) Wang, Z.; Lee, J. H.; Lu, Y., Label-Free Colorimetric Detection of Lead Ions with a Nanomolar Detection Limit and Tunable Dynamic Range by Using Gold Nanoparticles and DNAzyme. Adv. Mater. 2008, 20, 3263-3267.

(44) Wei, H.; Li, B.; Li, J.; Wang, E.; Dong, S., Simple and Sensitive Aptamer-Based Colorimetric Sensing of Protein Using Unmodified Gold Nanoparticle Probes. Chem. Commun. 2007, 3735-3737.

(45) Karsisiotis, A. I.; Hessari, N. M. a.; Novellino, E.; Spada, G. P.; Randazzo, A.; Webba da Silva, M., Topological Characterization of Nucleic Acid G-Quadruplexes by UV Absorption and Circular Dichroism. Angew. Chem., Int. Ed. 2011, 50, 10645-10648. 
(46) Liu, W.; Zhu, H.; Zheng, B.; Cheng, S.; Fu, Y.; Li, W.; Lau, T.-C.; Liang, H., Kinetics and Mechanism of G-Quadruplex Formation and Conformational Switch in a G-Quadruplex of PS2.M Induced by $\mathrm{Pb}^{2+}$. Nucleic Acids Res. 2012, 40, 4229-4236. 